\title{
AN INFRARED ISOTOPE ANALYZER
}

\author{
by J. C. KLUYVER and J. M. W. MILATZ
}

Physisch Laboratorium der Rijksuniversiteit te Utrecht, Nederland

\begin{abstract}
Synopsis
The shift in the infrared absorption bands of isotopic molecules is used in a new method for determining the isotope ratios in tracer experiments. The infrared absorption is measured with a non-dispersive filter instrument containing as selective detector a gas cell filled with a concentrated sample of the component to be measured. An instrument is devised according to this method, to measure the ${ }^{13} \mathrm{C} /{ }^{12} \mathrm{C}$ ratio in carbon dioxide. It permits the measurement of the ${ }^{13} \mathrm{C}$ abundance in $30 \mathrm{mg}$ carbon dioxide with an error of 0.005 at. $\%$ in the neighbourhood of the natural abundance of 1.1 at. $\%$. This precision is sufficient for the majority of tracer experiments. A more detailed account of this study is to be found in the thesis ${ }^{5}$ ) of one of us.
\end{abstract}

$\S 1$. Introduction. A method for determining the abundance ratio of stable isotopes based on the difference in infrared absorption spectra of isotopic molecules was suggested in a previous paper ${ }^{1}$ ). 'This method is here applied to the determination of the ${ }^{13} \mathrm{C} /{ }^{12} \mathrm{C}$ ratio in carbon dioxide. The $\nu_{3}$ bands of ${ }^{12} \mathrm{CO}_{2}$ and ${ }^{13} \mathrm{CO}_{2}$ have been measured by $\mathrm{N}$ i e $1 \mathrm{se} \mathrm{n}$ and $\mathrm{YaO}{ }^{2}$ ) and show an isotope shift of the band centers from 2350 to $2284 \mathrm{~cm}^{-1}$, and although the $P$-branch of ${ }^{12} \mathrm{CO}_{2}$ and the $R$-branch of ${ }^{13} \mathrm{CO}_{2}$ overlap, the $P$-branch of ${ }^{13} \mathrm{CO}_{2}$ is clear, at least for the small optical depths employed.

This difference in absorption between the same amount of normal and isotopic carbon dioxide is measured with a non-dispersive double beam gas analyzer ( $(2$, fig. 1$)$. In this type of analyzer the spectral sensitivity of the detector is exactly matched to the absorption in the analysis cell, as the detector consists of a gas cell filled with isotopic carbon dioxide, and the pressure rise caused by absorption in this gas cell indicates the intensity of the radiation. The doublebeam detector contains two adjacent cells, whose partition wall serves as the membrane in a condenser microphone. Chopped radiation is used. The difference in the pressure oscillations in the two cells brings about membrane oscillations and these capacity oscillations cause voltage oscillations, which are amplified and measured 
with an alternating current galvanometer. The amplitude of the pressure oscillations depends on the composition of the beams entering the detection cells and these depend on the absorption in the analysis cells and consequently on the percentage ${ }^{13} \mathrm{CO}_{2}$ in the carbon dioxide. Generally one analysis cell is filled with the sample to be analyzed and the other with normal carbon dioxide. Beforehand the isotope analyzer has to be calibrated with samples of known isotopic constitution. The smallest isotope enrichment, which can be measured, and the size of the sample needed characterize the value of the isotope analyzer ( $(5)$. The first quantity is determined by the smallest galvanometer deflection which can be mcasured (\$4) and the slope of the calibration curve: deflection versus ${ }^{13} \mathrm{C}$ content of the sample (§ 3 ).

$\S 2$. Description of the analyzer. A schematic diagram of the isotope analyzer is presented in fig. 1 . The sources are ordinary nichrome spirals mounted on conical plaster, and are heated by 50 Watts each. Thin mica windows protect the spirals against air currents from the chopper disc. The intensities of the beams may be balanced by iris diaphragms, shutters are also present. The analysis cells, $60 \mathrm{~mm}$ long,

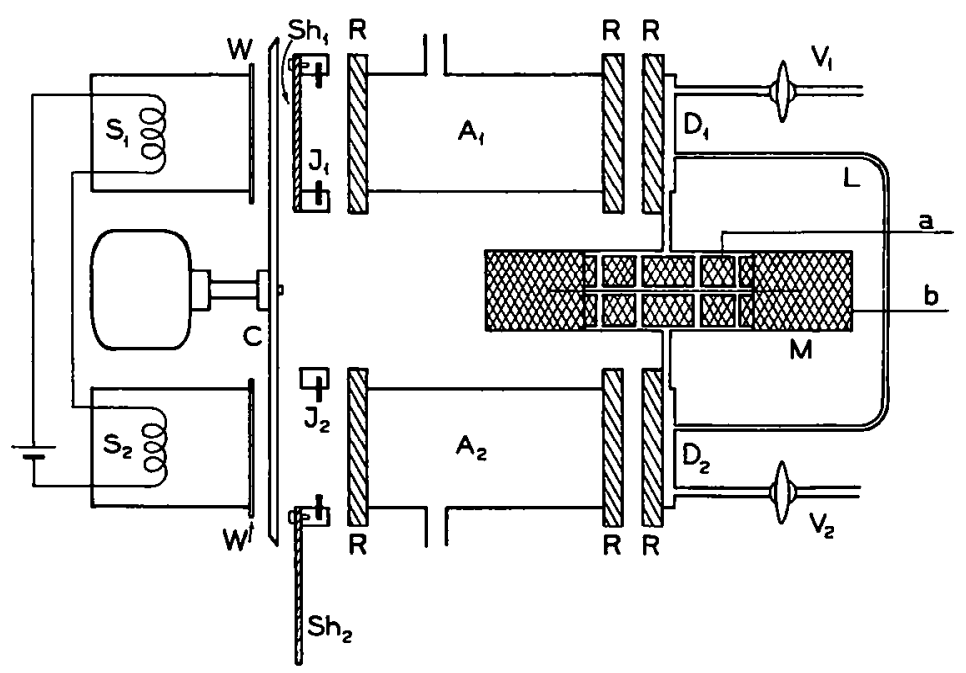

Fig. 1. Schematic drawing of the infrared isotope analyzer.

$\mathrm{S}_{1,2}=$ sources, $\mathrm{W}=$ mica window, $\mathrm{C}=$ chopper disc, $\mathrm{Sh}_{1,2}=$ shutters, $I_{1,2}=$ iris diaphragms, $R=$ rocksalt window, $A_{1}=$ analysis cell, $A_{2}=$ reference cell, $D_{1,2}=$ detection cells, $M=$ condenser microphone, $V_{1,2}=$ valves, $\mathrm{L}=$ capillary leak; $\mathbf{a}$ and $\mathrm{b}$ lead to the amplifierset. 
have rocksalt windows and aluminium reflecting walls. The detection cells are $3 \mathrm{~mm}$ long and have a diameter of $30 \mathrm{~mm}$. By pierced electrodes their volumes are connected to the $50 \mu$ wide space between electrodes and partition membrane. The capacitance of the microphone is of the order of $150 \mathrm{pF}$. A polarization voltage of about $60 \mathrm{~V}$ is used. Moreover, to prevent a displacement of the equilibrium position of the membrane by a fortuitous temperature rise in one of the cells, a capillary $1.6 \mathrm{~mm}$ wide and $15 \mathrm{~cm}$ long connects the two cells. This capillary is a leak for slow and a high resistance for rapid pressure changes. The microphone is backed by the alternating current amplificr and galvanometer sct developed in this laboratory ${ }^{3}$ ). This set provides a favorable signal to noise ratio, as it is only sensitive to signals of $50 \pm 1 \mathrm{c} / \mathrm{s}$. For this reason the interruption frequency was chosen to be $50 \mathrm{c} / \mathrm{s}$. To give the signals from both beams the optimal phase, the centre of the chopper disc should be exactly in the middle between the two analysis cells. The whole analyzer is placed in an aluminium box togethar with the first stage of the amplifier to avoid interference from carbon dioxide streaks in the air of the laboratory room. This box is placed on "vinycel" to shield the microphone from vibrations of the table.

By means of a gas-handling system, analogous to that of $\mathrm{J}$ a $\mathrm{n}$ $\mathrm{n}$ e $\mathrm{y}$ and $\mathrm{M}$ o y e $\mathrm{r}^{4}$ ), the analysis and reference cell may be filled respectively with the sample and standard carbon dioxide to the desired pressure. As the equality of the pressures in both cells is more important than the exact value of these pressures (see $\S 3$ ), one starts by filling the cells each to about $200 \mathrm{~mm}$, reading on a rough manometer. Next the pressure difference is measured on an inclined differential manometer and nullified by adjusting the pressure with a volume regulator. For more detailed description of the apparatus the reader is referred to the thesis of one of us ${ }^{5}$ ).

\$3. The choice of optimal conditions. The slope of the calibration curve indicates (cf. fig. 4 and 5) the sensitivity of the isotope analyzer, defined as the ability to distinguish between the two isotopic molecules and may be expressed in the percentage decrease of the signal effected by a $1 \%{ }^{13} \mathrm{CO}_{2}$ increase in the sample in the analysis cell. The term "unattenuated signal" is used here for the deflection of the galvanometer caused by a single beam having passed an evacuated analysis cell. 
The sensitivity of the isotope analyzer is determined by the length of the analysis cell: $d_{A}$, of the detection cell: $d_{D}$ and by the pressure in the analysis cell: $p_{A}$ and in the detection cell $p_{D}$.

However, $d_{D}$ and $p_{D}$ also influence the size of the signal. The optimal values of $d_{A}, d_{D}, p_{A}$ and $p_{D}$ are those which give the largest absolute change in signal for a $1 \%{ }^{13} \mathrm{C}$ increase in the sample. The sensitivity is only important so far as it contributes to this aim. Moreover the minimum amount of sample needed for an analysis has to be considered.

Due to the shape of the absorption bands, the influence of pressure broadening and the overlapping of the ${ }^{12} \mathrm{CO}_{2}$ and ${ }^{13} \mathrm{CO}_{2}$ bands, the problem of the optimal conditions is too complicated to be solved by calculation. A calculation leads to the optimal value of $d_{D}$, but the others had to be found by experiment.

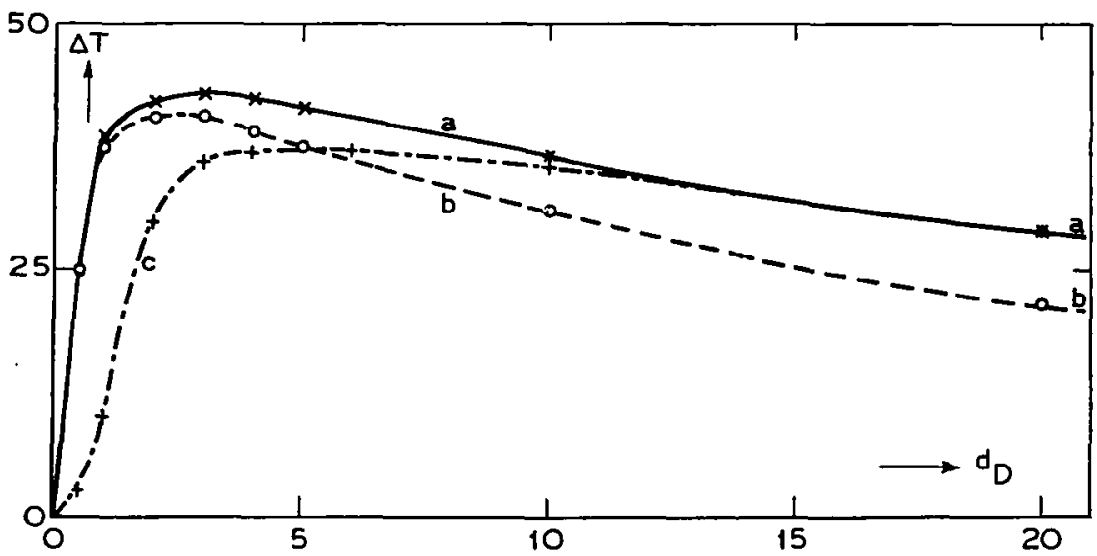

Fig. 2. The temperature oscillations in the detection cell $(\Delta T)$ as a function of the cell length $d_{D}$ in $\mathrm{mm}$. a) interruption frequency $=50 \mathrm{c} / \mathrm{s} ; \beta=0.54 \mathrm{~cm}^{-1}$

$\begin{array}{lll}\text { b) } \quad \text { c) } & \text { " } & =50 \mathrm{c} / \mathrm{s} ; \beta=0.92 \mathrm{~cm}^{-1} \\ \text { c) } & \text { " } & =5 \mathrm{c} / \mathrm{s} ; \beta=0.54 \mathrm{~cm}^{-1}\end{array}$

The scale of $\Delta T$ for curve $c$ is $10 \times$ the scale for curves $a$ and $b$.

The signal will be the larger the higher the absorbed energy per unit volume in the detection cell. As the intensity of the beam decreases in passing the cell, a shallow cell is desired. A lower limit is imposed on $d_{D}$ by the heat conduction to the walls during the time of exposure and by the influence of the dead volume in the microphone on the volume average of the absorbed energy.

The temperature in the detection cell as a function of time has been calculated ${ }^{5}$ ) by solving Fourier's equation with an additional 
term for heat production under the actual boundary conditions. The result for the dependence of the temperature oscillations $\Delta T$ on the cell length $d_{D}$ is presented in fig. 2, both for the actual interruption frequency of $50 \mathrm{c} / \mathrm{s}$ and for $5 \mathrm{c} / \mathrm{s}$. As the correct value of the absorption coefficient $(\beta)$ averaged over the absorption band is disputable, two values have been used. Both these values indicate a maximum $\Delta T$ near $d_{D}=3 \mathrm{~mm}$, and experiments corroborate this value.

The following experiments were made with a provisional instrument using only one beam and the detection cells filled with carbon dioxide containing $52.5 \%{ }^{13} \mathrm{CO}_{2}$ (the highest percentage obtainablc), kindly placed at our disposal by the Eastman Kodak Company as barium carbonate.

With $d_{D}=3 \mathrm{~mm}$ and $d_{A}=120 \mathrm{~mm}$ a series of absorption curves were measured both for normal and $52.5 \%$ isotopic carbon dioxide and $p_{D}$ as parameter. From these $p_{A}=150 \mathrm{~mm}$ and $p_{D}=380 \mathrm{~mm}$ appeared as the most favorable pressures.

Next three lengths of analysis cells were tried, viz. 60, 120 and 300 $\mathrm{mm}$, the corresponding optimal values of $p_{A}$ were 200,150 and 150 $\mathrm{mm}$. In these three cases the isotope effect was roughly the same and therefore $d_{A}=60 \mathrm{~mm}, p_{A}=300 \mathrm{~mm}$ were chosen, as this combination needs the smallest sample. Finally $p_{D}$ was varied anew and $p_{D}=400 \mathrm{~mm}$ proved to be the optimal value indeed.

After many technical improvements had been made and the analyzer was developed into the double-beam instrument described in $\S 2$, the sensitivity was remeasured (using a single beam), by taking the absorption curves (fig. 3) of carbon dioxide containing $1.1 \%$ and $3.2 \%{ }^{13} \mathrm{CO}_{2}$, and found to be $3 \%$ for $p_{A}=200 \mathrm{~mm}$ and $3.5 \%$ for $p_{A}=300 \mathrm{~mm}$, the further data being $p_{D}=400 \mathrm{~mm}$, $d_{D}=3 \mathrm{~mm}$ and $d_{A}=60 \mathrm{~mm}$. So if a sufficient amount of sample is available the latter value for $p_{A}$ is to be preferred.

From fig. 3 it is evident that the calibration curves depend little on the exact value of $p_{A}$. Hence it is more essential that the pressure in the analysis cell equals the pressure in the reference cell, than that exactly the same value for $p_{A}$ is always used.

$\S 4$. The measuring accuracy. From the value of the sensitivity found in the previous section ensues that the determination of $0.01 \%{ }^{13} \mathrm{C}$ requires a precision in the measurement of the signal of 
$0.03 \%$ of an unattenuated single beam. To attain this goal a doublebeam instrument had to be chosen and all avoidable causes of fluctuations had to be eliminated carefully. Three sources of fluctuations are, however, inevitable: a) fluctuations in the intensities of the beams, b) mechanical vibrations of the microphone membrane, c) amplifier noise. The fluctuations in the intensities of the beams may be caused either by current fluctuations through the sources, or temperature fluctuations of the sources by draught, or fluctuations in the absorption by carbon dioxide in the air in the beam. By increasing the intensities of the beams, the first cause of noise can always be made the limiting one in the signal to noisc ratio. Howcver, the smaller the other two noise generators are, the smaller intensities may be used. A reduction of the power consumption of the sources diminishes the stabilization problems.

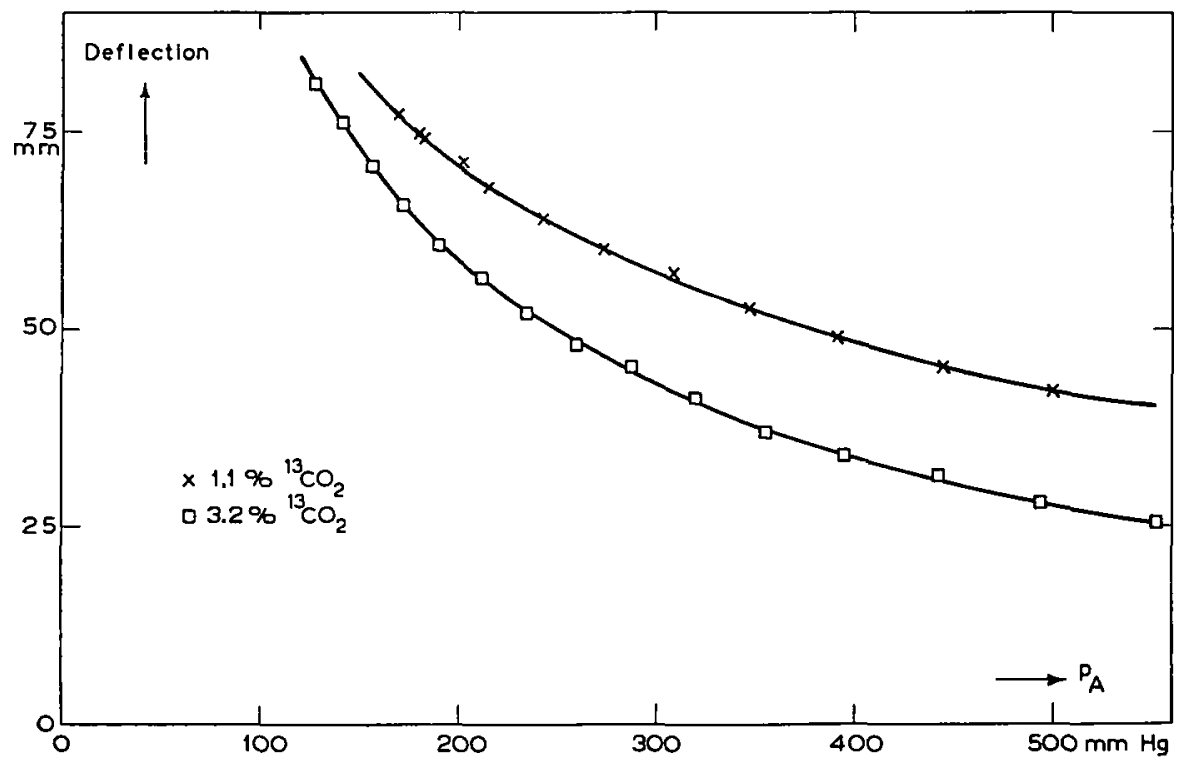

Fig. 3. Absorption curves of carbon dioxide containing $1.1 \%$ and $3.2 \%$

${ }^{13} \mathrm{CO}_{2} \cdot 100 \%$ transmission $=205 \mathrm{~mm}$ deflection.

$p_{D}=400$ inn $\mathrm{Hg}, d_{D}=3 \mathrm{~mm}$ and $d_{A}=60 \mathrm{~mm}$.

As the same current passes through both sources, the influence of fluctuations is greatly reduced. A $1 \%$ variation of the current causes a $2 \%$ variation in the intensity in the carbon dioxide band, but only a deviation of the zero of the double beam detector, equivalent to $0.1 \%$ of the unattenuated signal. 
In our instrument in the final version the amplifier noise (peak to peak value $0.08 \%$ of the single beam signal, indication time $1 \mathrm{sec}$ ) can be neglected compared to the vibrations of the unexposed detector $(0.4 \%)$ and these are only a fraction of the total noise $(1 \%$ of the unattenuated signal), which is caused mainly by fluctuations in the intensities of the beams. When the analysis cell is filled with the sample to be analyzed, the signal is reduced 3 times and the noise to $0.6 \%$ of the unreduced signal. In view of these peak to peak values it is safe to conclude that a reading with a precision of $0.5 \%$ of the transmitted signal can be made, especially as usually the galvanometer position is recorded for one minute (see $\$ 5$ ).

The smallest signal which can be measured (indication time $1 \mathrm{sec}$ ) corresponds to a $50 \mathrm{c} / \mathrm{s}$ oscillation of the membrane with an amplitude of the order of $4 \times 10^{-2}$ Angström. This is equivalent to an intensity of the beam of $0.01 \mathrm{erg} \mathrm{cm}^{-2} \mathrm{sec}^{-1}$.

A bolometer with the same sensitivity would have an efficiency of $3 \%$ calculated as by $\mathrm{B} \mathrm{e} \mathrm{c} \mathrm{k}$ in $\mathrm{g}^{8}$ ).

From fig. 3 may be deduced, that a rise in the pressure of $1 \mathrm{~mm}$ $\mathrm{Hg}$ in one analysis cell will change the percentage transmission with $0.5 \%$. The inclined differential manometer permits readings of 0.2 $\mathrm{mm} \mathrm{Hg}$ corresponding to $0.03 \%$ of the transmitted signal, and the pressure can be regulated with this accuracy.

$\S 5$. Results. To obtain reproducible results it is necessary to switch on the sources and chopper disc one hour before taking measurements, in order to reach temperature equilibrium of the various components. The following method of measuring has been used. First the zero line is recorded for one minute with normal carbon dioxide in both analysis cells to the same pressure, then one ccll is emptied and refilled to the same pressure with the sample to be analyzed, and the new position of the galvanometer is recorded. Usually the standard and unkown are alternated thrice in one determination, and moreover, to indicate the overall sensitivity of the analyzer during this analysis, the signal produced by a single beam passing an evacuated analysis cell is recorded (with a reduced sensitivity of the amplifier). The time needed for one analysis is about $30 \mathrm{~min}$. Practically no carbon dioxide is lost by filling and emptying the cells and storing in the traps. Therefore, the amount of 
sample required, $30 \mathrm{mg}$, is independent of the number of measurements one desires to take.

The results of calibration with samples containing 1.1, 1.2, 1.3 and 1.5 at. $\%{ }^{13} \mathrm{CO}_{2}$ are shown in Table I and fig. $4, p_{A}$ being $200 \mathrm{~mm}$. The

TABLE I

\begin{tabular}{|c|rrr|c|c|c|}
\hline \multicolumn{8}{|c|}{ Calibration of the analyzer } \\
\hline $\begin{array}{c}\% \text { atom } \\
\text { excess }{ }^{13} \mathrm{C}\end{array}$ & \multicolumn{2}{|c|}{$\begin{array}{c}\text { deflection } \\
\text { in mm }\end{array}$} & $\begin{array}{c}\text { mean } \\
\text { deflection } \\
\text { in mm }\end{array}$ & $\begin{array}{c}\text { single beam } \\
\text { signal } \\
\text { in mm }\end{array}$ & $\begin{array}{c}\% \text { trans- } \\
\text { mission }\end{array}$ \\
\hline 0.1 & $7^{5}$, & 8, & $8-$ & $8^{-}$ & 1910 & 0.41 \\
0.2 & 14, & $15^{5}$, & 15 & $15^{-}$ & 1910 & 0.78 \\
0.4 & 30, & $29+$, & 29 & $29^{5}$ & 1930 & 1.53 \\
0.1 & 7, & 7, & $7-$ & 7 & 1740 & 0.40 \\
0.2 & $14-$, & 14, & 14 & 14 & 1740 & 0.80 \\
0.4 & 29, & 28, & $28^{5}$ & $28^{5}$ & 1810 & 1.57 \\
\hline
\end{tabular}

interval between the two series of measurements was three days and the reproducibility is good, even while in the mean time the analysis cells had been taken out and replaced. Fig. 5 demonstrates a calibration curve over a larger range of ${ }^{13} \mathrm{C}$ percentages with $p_{A}=300 \mathrm{~mm}$.

When the highest accuracy is desired in the neighbourhood of the natural abundance of $1.1 \%{ }^{13} \mathrm{C}$, a sample with $0.1 \%$ excess ${ }^{13} \mathrm{C}$ will cause a deflection of $30 \mathrm{~mm}$, and the peak value of the noise will be 3 $\mathrm{mm}$ on the same recording paper (fig. 6).

From these data it is concluded, that a precision of 0.005 at $\%{ }^{13} \mathrm{C}$ can be reached in 3 measurements of a sample containing $30 \mathrm{mg}$ carbon dioxide.

Replacement of the alternating current galvanometer by a penrecorder, with a high-speed telegraph relay to ensure the small band width, also led to satisfactory results.

As the isotope ratios are deduced from a calibration most systematical errors are excluded. As the absorption bands of ${ }^{12} \mathrm{C}^{16} \mathrm{O}^{17} \mathrm{O}$ and ${ }^{12} \mathrm{C}^{16} \mathrm{O}^{18} \mathrm{O}$ are also shifted with respect to the ${ }^{12} \mathrm{C}^{16} \mathrm{O}_{2}$ band, the ${ }^{17} \mathrm{O}$ and ${ }^{18} \mathrm{O}$ abundance in the sample should be the same as in the standards. Fortunately the ${ }^{18} \mathrm{O}$ and ${ }^{17} \mathrm{O}$ abundance is very small, $0.20 \%$ and $0.04 \%$, and variations in nature do not amount to more than a few percents of these values. Taking a pessimistic point of view the limit of error in the ${ }^{13} \mathrm{C}$ determination due to ${ }^{18} \mathrm{O}$ variations is $0.008 \%{ }^{13} \mathrm{C}$.

To demonstrate the usefulness of the isotope analyzer the ${ }^{13} \mathrm{C}$ abundance of various carbon containing materials was measured 


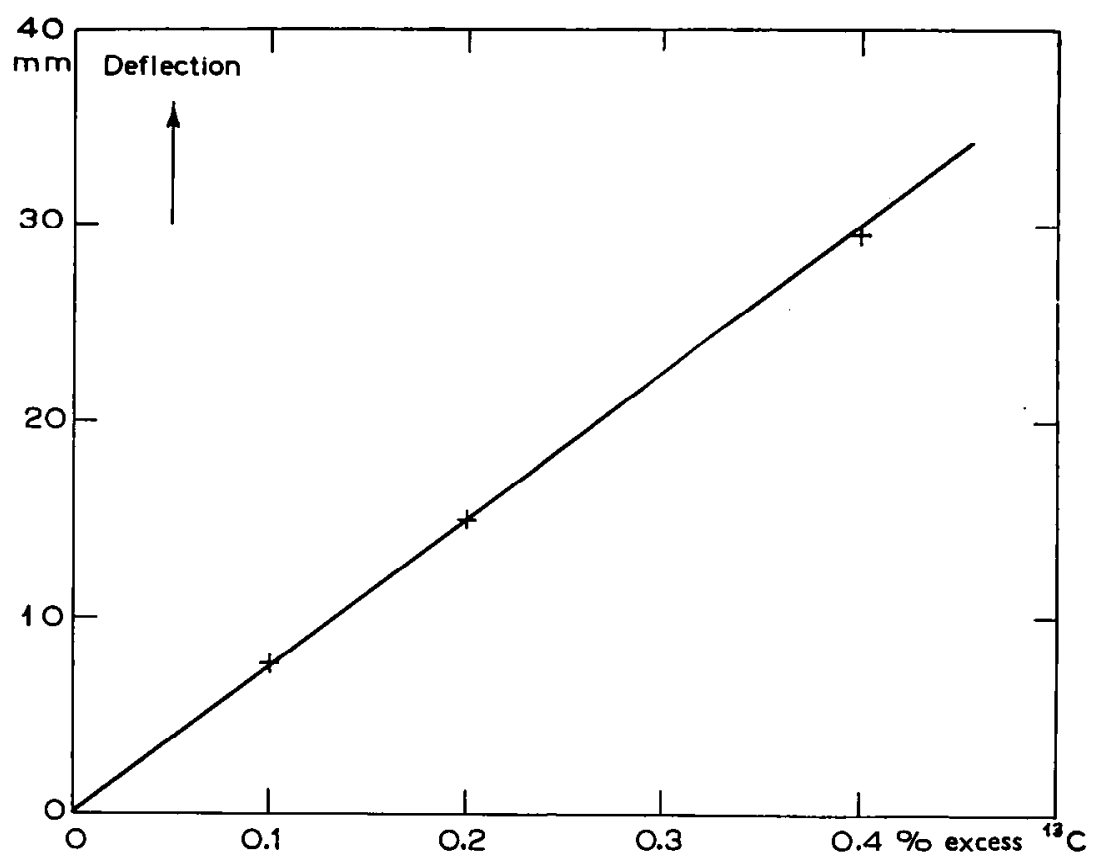

Fig. 4. Calibration curve showing the deflection in $\mathrm{mm}$ versus the ${ }^{13} \mathrm{C}$ content of the sample; $p_{A}=200 \mathrm{~mm} \mathrm{Hg}$.

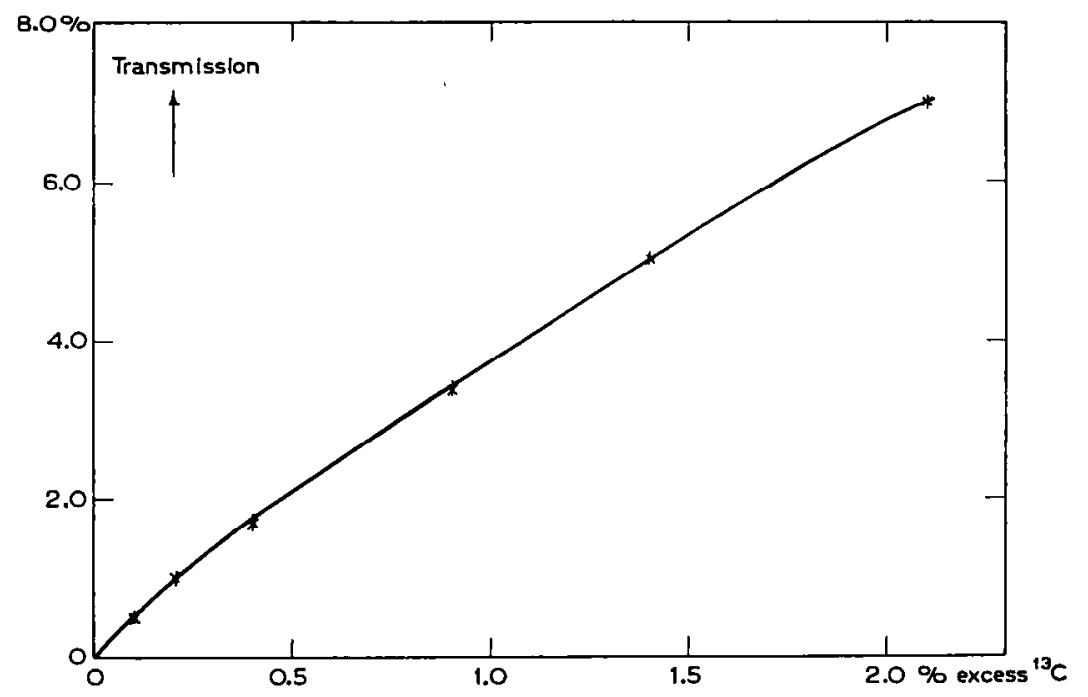

Fig. 5. Calibration curve showing the deflection in $\%$ transmission versus the ${ }^{13} \mathrm{C}$ content of the sample; $p_{A}=300 \mathrm{~mm} \mathrm{Hg}$. 


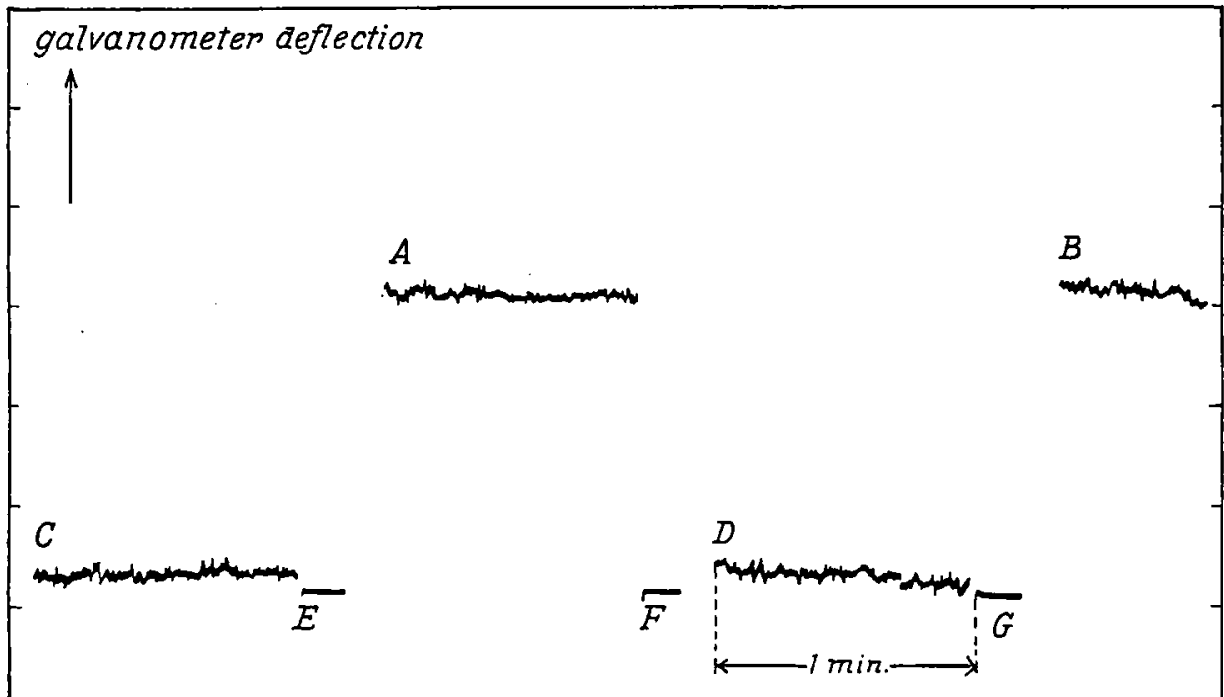

Fig. 6. The measurement of a sample containing $1.2 \%{ }^{13} \mathrm{CO}_{2}$ at high sensitivity, $p_{A}=300 \mathrm{~min}, 25 \mathrm{~mm}=1$ minute.

$A$ and $B: 1.2 \%{ }^{13} \mathrm{CO}_{2}$ in the analysis cell and $1.1 \%{ }^{13} \mathrm{CO}_{2}$ in the reference cell. $C$ and $D: 1.1 \%{ }^{13} \mathrm{CO}_{2}$ in both analysis and reference cell (zero line).

$F, F$ and $G$ : galvanometer zeru.

and slight variations were found in agreement with other authors $\left.{ }^{6}\right)^{7}$ ). All values given in Table II are reduced to the ${ }^{13} \mathrm{C}$ percentage of sea water, which was measured to be $1.107 \%$ by $\mathrm{M} \mathrm{urphey}$ and $\mathrm{N}$ i e ${ }^{6}$ ). The reference cell was filled with carbon dioxide from $\mathrm{BaCO}_{3}$ pro analyse which had accidentally the same isotope ratio as sea water.

TABLE II

\begin{tabular}{|c|c|c|c|c|c|}
\hline \multicolumn{6}{|c|}{${ }^{13} \mathrm{C}$ abundance in various substances } \\
\hline Origin of Carbon & $\begin{array}{l}p_{A} \text { in } \\
\mathrm{mm} \mathrm{Hg}\end{array}$ & $\begin{array}{l}\text { Deflection } \\
\text { by } 0.10 \% \\
{ }^{13} \mathrm{C} \text { in } \mathrm{mm}\end{array}$ & $\begin{array}{l}\text { Measured } \\
\text { deflection } \\
\text { in } \mathrm{mm}\end{array}$ & $\begin{array}{l}\% \text { excess } \\
{ }^{13} \mathrm{C}\end{array}$ & $\%{ }^{13} \mathrm{C}$ \\
\hline \multicolumn{6}{|l|}{$\begin{array}{c}\mathrm{BaCO}_{3} \text { pro analyse } \\
\text { (limestone?) }\end{array}$} \\
\hline Sea water & 200 & 24 & 0 & 0.000 & 1.107 \\
\hline Shells & 300 & 29 & 3 & 0.010 & 1.117 \\
\hline Air & 200 & 24 & $-4^{+}$ & -0.018 & 1.089 \\
\hline $\mathrm{CO}_{2}$ cylinder & 300 & $27^{5}$ & $-7^{5}$ & -0.027 & 1.080 \\
\hline Breath & 300 & $20^{5}$ & $-7^{-}$ & -0.033 & 1.074 \\
\hline Agave & 200 & $17^{\mathrm{s}}$ & -2 & -0.011 & 1.096 \\
\hline Spinach & 200 & $17^{5}$ & -5 & -0.029 & 1.078 \\
\hline & & & & \pm 0.005 & \pm 0.005 \\
\hline
\end{tabular}


$\S 6$. Conclusions. The sensitivity of the isotope analyzer of $0.005 \%$ ${ }^{13} \mathrm{C}$ with a sample of $30 \mathrm{mg}$ carbon dioxide is sufficient for many tracer experiments. Moreover, smaller samples can be analyzed if sensitivity is sacrificed, for instance $15 \mathrm{mg}$ with $0.008 \%{ }^{13} \mathrm{C}$ precision.

The simplicity and inherent low price both in initial price and in maintenance costs is a valuable asset to the isotope analyzer compared to the mass spectrometer, which surpasses the analyzer in sensitivity, but needs skilled personnel for maintenance.

Among several possible technical improvements of the instrument the reduction of the chopper frequency may be mentioned. The size of the signal is roughly proportional to the time of exposure of the detection cells and hence a reduction of the frequency will give a gain in signal.

Experiments to reduce further the minimum amount of carbon dioxide of a sample are under way, and also the application of the method to the determination of the $H / D$ ratio in water vapour is envisaged.

The help in the experiments of J. Harde bol, J. J. A. Moo y and $\mathrm{C}$. v a $\mathrm{n}$ d e r L e u $\mathrm{n}$ is gratefully acknowledged.

This investigation is part of the research programme of the "Stichting voor Fundamenteel Onderzoek der Materie" and was made possible by financial support from the "Nederlandse Organisatie voor Zuiver Wetenschappelijk Onderzoek".

Received 23-2-'53.

\section{REFERENCES}

1) Milatz, J. M. W., Kluyver, J. C. and Hardebol, J., J. chem. Phys. 1) (1951) 887 .

2) Nielsen, A. H. and Y a o, Y. T., Phys. Rev. 68 (1945) 173.

3) M i l a tz, J. M. W. and B l o e m berge $\mathrm{n}$, N., Physica 11 (1946) 449.

4) J a n ne y, C. D. and M o yer, B. J., Rev. sci. Inst., 19 (1948) 667.

5) Kl u y ver, J. C., Infrared Isotópe Analysis, Thesis Utrecht 1952.

6) M u r phe y, B. F. and Nier, A. O., Phys. Rev. 59 (1941) 771.

7) Thode, H. G., Research 2 (1949) 154.

8) Becking, A. G. Th., Fluctuatievcrschijnselen bij bolometers, Thesis Utrecht 1952. 